Author information:. Corresponding Author and Address for Correspondence: Jeff C. Huffman, M.D., Massachusetts General Hospital, 55 Fruit Street Boston, MA 02114, Phone: 617-724-2910, Fax: 617-724-9155, jhuffman@ partners.org.

Elizabeth N. Madva: Affiliation: Massachusetts General Hospital, Address: 55 Fruit St. Boston, MA 02114, Phone: 617-726-2000 Federico Gomez-Bernal: Affiliation: Massachusetts General Hospital, Address: 55 Fruit St. Boston, MA 02114, Phone: 857-364-7374

Rachel A. Millstein: Affiliation: Massachusetts General Hospital, Address: 55 Fruit St. Boston, MA 02114, Phone: 617-724-2047

Christopher M. Celano: Affiliation: Massachusetts General Hospital, Address: 55 Fruit St. Boston, MA 02114, Phone: 617-726-6485

Elyse R. Park: Affiliation: Massachusetts General Hospital, Address: 1 Bowdoin Square, Boston, MA 02114, Phone: 617-724-6836

Carol A. Mastromauro: Affiliation: Massachusetts General Hospital, Address: 55 Fruit St. Boston, MA 02114, Phone: 617-724-9140

Ariana M. Albanese: Affiliation: Massachusetts General Hospital, Address: 55 Fruit St. Boston, MA 02114, Phone: 617-643-0871

Eleanor E. Beale: Affiliation: Massachusetts General Hospital, Address: 55 Fruit St. Boston, MA 02114, Phone: 617-724-9141

Jeff C. Huffman: Affiliation: Massachusetts General Hospital, Address: 55 Fruit St. Boston, MA 02114 Phone: 617-724-2910

Conflicts of Interest and Sources of Funding:

Time for analysis and article preparation was funded by the National Heart, Lung, and Blood Institute through grants K23HL123607 (to Dr. Celano) and grants R21DK109313 and R01HL113272 (to Dr. Huffman). The content is solely the responsibility of the authors and does not represent the official views of the National Institutes of Health or other funders. Sponsors had no role in the design, analysis, interpretation, or publication of the study. 
001) in mid-life adults. Interventions that target the specific needs of this population could reduce distress, improve health behaviors, and have a major impact on public health.

\section{Keywords}

acute coronary syndrome; chronic medical conditions; diabetes; heart failure; mid-life

\section{Introduction}

Mid-life-ages 50 to 64 -is a critical time period for health. Many chronic medical conditions (CMCs) manifest during this period and the majority of mid-life adults have at least one CMC (CDC, 2009, 2012). The growing number of mid-life adults, and their frequent development of CMCs, make mid-life health a public health priority.

Suboptimal participation in healthy behaviors (e.g., physical activity and diet), potentially related to mid-life-specific social and psychological factors, likely contributes to CMC development in mid-life (Blackwell, Lucas, \& Clarke, 2014; Sun et al., 2010). Mid-life adults may face increased work responsibilities and caregiving burden (Dainese et al., 2011), high levels of psychiatric symptoms (Brody, 2014; Charlson et al., 2016; Coryell, 1988; Walker, McGee, \& Druss, 2015) and diminished optimism and positive affect (Steptoe, Deaton, \& Stone, 2015). These factors are linked to poor health behavior adherence and impaired medical prognosis.

Despite established links between psychosocial stressors, psychological status, and health behaviors, there has been limited study of these relationships in mid-life. Accordingly, we analyzed data from three studies of patients with CMCs (heart failure [HF], type 2 diabetes [T2D], and coronary artery disease [CAD]) that used quantitative self-report measures and qualitative interviews to examine patients' experiences. We compared differences in selfreported psychological symptoms between mid-life and non-mid-life persons and, using the semi-structured interviews, examined the frequency of stressors that can impede health behaviors. We hypothesized that mid-life persons with CMCs would report greater depression and anxiety, lower positive affect and optimism, and higher rates of specific (e.g., occupational) stressors than other adults with CMCs.

\section{Methods}

\section{Participants}

This mixed-methods analysis included participants hospitalized at an urban academic medical center enrolled in one of three studies. Study 1 (REACH for Health; $\mathrm{N}=30$ ) included adults with New York Heart Association class II/III HF. Study 2 (QRDM; N=29) enrolled adults with T2D. Study 3 (PEACE; N=33) included adults with an acute coronary syndrome. In all studies, patients were excluded if they were unable to be physically active, were cognitively impaired, had no phone access, or had medical conditions that precluded interviews or were imminently terminal. All studies received Institutional Review Board approval. 


\section{Procedures}

Self-report measures-During hospitalization, participants completed the Hospital Anxiety and Depression Scale (HADS) anxiety and depression subscales (Zigmond and Snaith, 1983), the Life Orientation Test-Revised (LOT-R) optimism scale (Scheier, Carver, \& Bridges, 1994), and positive affect items from the Positive Affect Negative Affect Schedule (PANAS) (Watson, Clark, \& Tellegen, 1988). Cronbach's alpha for the three scales in this analysis was $a=0.83, a=0.80$, and $a=0.87$ respectively.

Qualitative Interviews-Semi-structured interviews (see Appendix) were completed at bedside by trained staff. Interview guides were created using a model (Bouchard, Shephard, \& Stephens, 1993; Huffman, DuBois, Millstein, Celano, \& Wexler, 2015) outlining contributors to health behavior adherence. Interviews focused on experience of medical illness, barriers to health behaviors, and psychological states. All interviews were recorded and transcripts reviewed for accuracy by the interviewer, and they were performed until thematic saturation was achieved (Guest, Bunce, \& Johnson, 2006).

Analysis-To compare mid-life and non-mid-life persons on self-report measures, we utilized independent samples t-tests for bivariate analysis, and multivariable linear regression controlling for study/primary CMC. For qualitative analyses, two readers, blinded to participant age, reviewed transcripts, conducted content analysis, and coded interviews for the presence/absence of general barriers (chronic pain, medical comorbidities, fatigue, and arthritis) (Badley and Ansari, 2010; Gillette, Petrescu-Prahova, Herting, \& Belza, 2015; McPhail, Schippers, Marshall, Waite, \& Kuipers, 2014) and potential mid-life-specific barriers (occupational stress, financial strain, time burden, and caregiving burden (Lachman, Teshale, \& Agrigoroaei, 2015)) linked to reduced health behavior participation. Twenty percent of transcripts were coded by both reviewers (theme concordance: $\kappa=.94$ ); discrepancies were adjudicated via discussion and text review. Reviewers then derived themes among mid-life participants regarding the relationship between sources of distress and health behaviors. To assess between-group differences in these barriers, we performed chi-square analysis and multivariable regression controlling for study/CMC. Analyses were repeated excluding participants under age 50, as younger patients with these CMCs may represent outliers. Data analyses were performed using Stata 14.2 (StataCorp, College Station, TX), and statistical tests were two-tailed $(a=.05)$.

\section{Results}

Ninety-two participants ( $\mathrm{n}=30$ mid-life) completed quantitative assessments (see Table 1 for participant characteristics).

\section{Self-report measures}

Mid-life participants ( $\mathrm{n}=30)$ reported greater distress (depression/anxiety) than non-mid-life participants (HADS total—mid-life: 13.8 ( $\mathrm{SD}=7.3$ ) vs. non-mid-life: 10.6 ( $\mathrm{SD}=6.6$ ); $t(90)=2.13 ; p=.035$ ), with trends toward greater anxiety and depression on the HADS anxiety ( $\mathrm{p}=.075)$ and depression ( $\mathrm{p}=.054)$ subscales (Table 2$)$. More mid-life patients exceeded cutoffs for elevated anxiety (HADS subscale score> 7; mid-life: $33 \%$ vs. non-mid- 
life: $15 \%$ ) and depression (53\% with HADS-D>7 vs. $31 \%$ ). Mid-life participants also reported marginally lower positive affect on bivariate analysis ( $\mathrm{p}=.056)$. After removing participants $(n=8)$ with age $<50$, mid-life participants were found to have experienced significantly greater anxiety and depression (Table 2 and Supplementary Table 1).

\section{Qualitative interviews: between-group comparisons regarding barriers/stressors}

Eighty-eight semi-structured interviews were completed. There were no differences between mid-life $(\mathrm{n}=28)$ and non-mid-life $(\mathrm{n}=60)$ participants in experiencing decreased energy/ fatigue, medical comorbidities, chronic pain, or arthritis (Supplementary Table 2).

In contrast, several stressors were significantly more common in mid-life adults. These included occupational stress $(\mathrm{p}<.001)$, caregiving stress $(\mathrm{p}=.002)$, financial stress $(\mathrm{p}=.004)$, and time burden ( $\mathrm{p}<.001$; Table 3$)$. These findings held on logistic regression accounting for study cohort/CMC and when younger participants were removed (Supplementary Table 2.

\section{Themes from qualitative interviews among mid-life participants with CMCs}

Several stressors noted above were linked with impaired health behaviors in mid-life adults (see Table 4). Occupational stress was commonly reported as a key barrier to modifying unhealthy behaviors (e.g., diet). Caregiving stress, often related to parenting and providing care to spouses/elderly parents, commonly impeded health behaviors. Though less prominent, financial stress also impacted health behaviors via decreased time and resources. Finally, some mid-life adults noted a combination of these stressors, including higher-level occupations with greater responsibilities, caregiving across generations, stress of providing for families, and managing CMCs.

\section{Discussion}

We found that mid-life persons with CMCs, compared to non-mid-life participants, reported greater psychological distress and were vastly more likely to identify occupational, financial, time-related, and caregiving-related stressors as barriers to healthy behaviors.

Our finding that mid-life persons reported having greater psychological distress (with the majority of mid-life persons reporting elevated depressive symptoms) is consistent with prior findings. In the MID-life in the United States study (Brim, Ryff, \& Kessler, 2004), approximately $13 \%$ had elevated depressive symptoms and nearly $10 \%$ had an anxiety disorder (Gathuru, Odukoya, \& Thorpe, 2016; Grzywacz and Ettner, 2000). Other work has likewise found that $10 \%$ of mid-life adults have elevated depressive symptoms (CDC, 2011; Valenstein, Vijan, Zeber, Boehm, \& Buttar, 2001) Given that depression and anxiety are linked to poor health behavior completion, progression of CMCs, and mortality (Charlson, et al., 2016; Pederson, Warkentin, Majumdar, \& McAlister, 2016; Saint Onge, Krueger, \& Rogers, 2014), identification and management of these conditions is particularly important in mid-life persons with CMCs (Celano, Suarez, Mastromauro, Januzzi, \& Huffman, 2013).

Mid-life persons also reported somewhat lower positive affect. Diminished positive affect and psychological well-being is associated with lower function (Celano, Beale, Moore, Wexler, \& Huffman, 2013; Davis et al., 2015), less physical activity (Sin, Moskowitz, \& 
Whooley, 2015; White et al., 2012), and mortality (Chida and Steptoe, 2008; Giltay, Geleijnse, Zitman, Hoekstra, \& Schouten, 2004; Hevey, McGee, \& Horgan, 2014; A. Steptoe, Dockray, \& Wardle, 2009). Specifically in mid-life adults, positive psychological states are linked to lower rates of metabolic syndrome and diabetes (Boehm et al., 2013b; Boylan and Ryff, 2015; Tsenkova, Karlamangla, \& Ryff, 2016). Interventions to promote positive affect in medical patients (Bolier et al., 2013; Huffman et al., 2016; Peterson et al., 2012) may therefore be well-suited to mid-life persons with CMCs given their low positive affect and numerous stressors.

The finding that specific stressors related to work, finances, time, and caregiving are more common in mid-life persons with CMCs confirms prior work in non-disease populations (Almeida and Horn, 2004; Linn, Sandifer, \& Stein, 1985; Piazza, Charles, \& Almeida, 2007). These specific stressors were linked with suboptimal health behavior participation, which is, in turn, associated with lower function, more hospitalizations, and increased mortality.

This analysis had several limitations. First, we examined cross-sectional data in hospitalized patients. Hospitalization may have had a disproportionately greater effect on occupational and financial stressors in mid-life persons compared to older adults, and these findings may differ in a healthier community sample. Second, the interviews were not specifically designed to inquire about mid-life-stage specific stressors. Finally, we had only a moderate number of mid-life persons, requiring replication in a larger sample.

In conclusion, our study found that among hospitalized patients, mid-life adults with CMCs reported having more psychological distress and higher rates of specific psychosocial stressors than other adults, and these factors are linked to impaired health behavior adherence. Interventions targeted to the needs of this population, focusing on reducing stress and improving health behaviors, could have a major public health impact.

\section{Supplementary Material}

Refer to Web version on PubMed Central for supplementary material.

\section{References}

Almeida DM, \& Horn MC (2004). Is daily life more stressful during middle adulthood. How healthy are we, pp. 425-451.

Badley EM, \& Ansari H (2010). Arthritis and arthritis-attributable activity limitations in the United States and Canada: a cross-border comparison. Arthritis care \& research, 62(3), pp. 308-315. doi: 10.1002/acr.20100 Retrieved from 10.1002/acr.20100http://onlinelibrary.wiley.com/store/10.1002/ acr.20100/asset/20100_ftp.pdf? $v=1 \& \mathrm{t}=\mathrm{j} 3 \times 3 \mathrm{~b} 8 \mathrm{tr} \& \mathrm{~s}=\mathrm{a} 8920 \mathrm{f5ee} 47 \mathrm{cb} 0 \mathrm{e} 84 \mathrm{f} 1 \mathrm{bb} 386 \mathrm{a} 5 \mathrm{e} 42 \mathrm{ea} 55 \mathrm{~b} 75 \mathrm{eb} 22$ http://onlinelibrary.wiley.com/store/10.1002/acr.20100/asset/20100_ftp.pdf?

$\mathrm{v}=1 \& \mathrm{t}=\mathrm{j} 3 \times 3 \mathrm{bd} 87 \& \mathrm{~s}=\mathrm{c5}$ ed89bbd013d4760495bfbcddedf420afe08472 Retrieved from http:// onlinelibrary.wiley.com/store/10.1002/acr.20100/asset/20100_ftp.pdf?

$\mathrm{v}=1 \& \mathrm{t}=\mathrm{j} 3 \times 3 \mathrm{~b} 8 \mathrm{tr} \& \mathrm{~s}=\mathrm{a} 8920 \mathrm{f5ee} 47 \mathrm{cb} 0 \mathrm{e} 84 \mathrm{f} 1 \mathrm{bb} 386 \mathrm{a} 5 \mathrm{e} 42 \mathrm{ea} 55 \mathrm{~b} 75 \mathrm{eb} 22 \mathrm{http} / / /$ onlinelibrary.wiley.com/ store/10.1002/acr.20100/asset/20100_ftp.pdf?

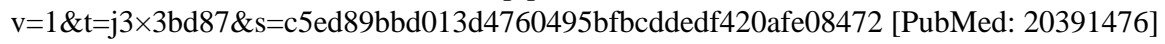

Blackwell DL, Lucas JW, \& Clarke TC (2014). Summary health statistics for US adults: national health interview survey, 2012. Vital and health statistics. Series 10, Data from the National Health Survey(260), pp. 1-161. 
Bolier L, Haverman M, Westerhof GJ, Riper H, Smit F, \& Bohlmeijer E (2013). Positive psychology interventions: a meta-analysis of randomized controlled studies. BMC public health, 13(1), p 119. [PubMed: 23390882]

Bouchard C, Shephard RJ, \& Stephens T (1993). Physical activity, fitness, and health: Human Kinetics Publishers.

Brim OG, Ryff CD, \& Kessler RC (2004). How healthy are we?: A national study of well-being at midlife: University of Chicago Press.

Brody DJ (2014). Depression in the US Household Population, 2009-2012.

CDC. (2009). Centers for Disease Control and Prevention (CDC)The Power of Prevention: Chronic disease...The public health challenge of the 21st century. Retrieved Date from https://www.cdc.gov/ chronicdisease/pdf/2009-power-of-prevention.pdf.

CDC. (2011). United States Centers for Disease Control. Diabetes: Successes and Opportunities for Population-Based Prevention and Control [United States Centers for Disease Control. Diabetes: Successes and Opportunities for Population-Based Prevention and Control]. Retrieved Date Accessed, 2014 from file://C:/Users/eeb34/Downloads/ DIABETES_SUCCESSES_AND_OPPORTUNITIES_FOR_POPULATI.pdf.

CDC. (2012). National Center for Health Statistics. Health, United States: With Special Feature on Emergency Care. Retrieved Date from https://www.cdc.gov/nchs/data/hus/hus12.pdf.

Celano CM, Beale EE, Moore SV, Wexler DJ, \& Huffman JC (2013). Positive psychological characteristics in diabetes: a review. Curr Diab Rep, 13(6), pp. 917-929. doi:10.1007/ s11892-013-0430-8 Retrieved from 10.1007/s11892-013-0430-8https://www.ncbi.nlm.nih.gov/ pubmed/24048687 Retrieved from https://www.ncbi.nlm.nih.gov/pubmed/24048687 [PubMed: 24048687]

Celano CM, Suarez L, Mastromauro C, Januzzi JL, \& Huffman JC (2013). Feasibility and utility of screening for depression and anxiety disorders in patients with cardiovascular disease. Circ Cardiovasc Qual Outcomes, 6(4), pp. 498-504. doi:10.1161/CIRCOUTCOMES.111.000049 Retrieved from 10.1161/CIRCOUTCOMES.111.000049https://www.ncbi.nlm.nih.gov/pubmed/ 23759474 Retrieved from https://www.ncbi.nlm.nih.gov/pubmed/23759474 [PubMed: 23759474]

Charlson FJ, Baxter AJ, Dua T, Degenhardt L, Whiteford HA, \& Vos T (2016). Excess Mortality from Mental, Neurological, and Substance Use Disorders in the Global Burden of Disease Study 2010 In Patel V, Chisholm D, Dua T, Laxminarayan R \& Medina-Mora ME (Eds.), Mental, Neurological, and Substance Use Disorders: Disease Control Priorities, Third Edition (Volume 4). Washington (DC): The International Bank for Reconstruction and Development / The World Bank (c) 2016 .

Chida Y, \& Steptoe A (2008). Positive psychological well-being and mortality: a quantitative review of prospective observational studies. Psychosomatic medicine, 70(7), pp. 741-756. [PubMed: 18725425]

Coryell WH (1988). Panic disorder and mortality. Psychiatric Clinics of North America

Dainese SM, Allemand M, Ribeiro N, Bayram S, Martin M, \& Ehlert U (2011). Protective factors in midlife: How do people stay healthy? GeroPsych: The Journal of Gerontopsychology and Geriatric Psychiatry, 24(1), p 19.

Davis JC, Bryan S, Li LC, Best JR, Hsu CL, Gomez C, . . . Liu-Ambrose T (2015). Mobility and cognition are associated with wellbeing and health related quality of life among older adults: a cross-sectional analysis of the Vancouver Falls Prevention Cohort. BMC Geriatr, 15, p 75. doi: 10.1186/s12877-015-0076-2 [PubMed: 26142897]

Gathuru IM, Odukoya OK, \& Thorpe JM (2016). Under Treatment of Depression Among Midlife and Older Adults in the United States. Social Pharmacy Journal (SPJ), 1(1)

Gillette DB, Petrescu-Prahova M, Herting JR, \& Belza B (2015). A Pilot Study of Determinants of Ongoing Participation in EnhanceFitness: A Community-Based Group Exercise Program for Older Adults. Journal of geriatric physical therapy 38(4), pp. 194-201. doi:10.1519/jpt. 0000000000000041 [PubMed: 25695473]

Giltay EJ, Geleijnse JM, Zitman FG, Hoekstra T, \& Schouten EG (2004). Dispositional Optimism and All-Cause and Cardiovascular Mortality ina Prospective Cohort of Elderly Dutch Men and Women. Archives of general psychiatry, 61(11), pp. 1126-1135. [PubMed: 15520360] 
Grzywacz J, \& Ettner SL (2000). Lost time on the job: the effect of depression versus physical health conditions. The Economics of Neuroscience, 2(6), pp. 41-46.

Guest G, Bunce A, \& Johnson L (2006). How many interviews are enough? An experiment with data saturation and variability. Field methods, 18(1), pp. 59-82.

Hevey D, McGee HM, \& Horgan JH (2014). Comparative optimism among patients with coronary heart disease (CHD) is associated with fewer adverse clinical events 12 months later. Journal of behavioral medicine, 37(2), pp. 300-307. [PubMed: 23274764]

Huffman JC, DuBois CM, Millstein RA, Celano CM, \& Wexler D (2015). Positive psychological interventions for patients with type 2 diabetes: rationale, theoretical model, and intervention development. Journal of diabetes research, 2015

Huffman JC, Millstein RA, Mastromauro CA, Moore SV, Celano CM, Bedoya CA, . . Januzzi JL (2016). A positive psychology intervention for patients with an acute coronary syndrome: treatment development and proof-of-concept trial. Journal of Happiness Studies, 17(5), pp. 19852006. [PubMed: 28082831]

Lachman ME, Teshale S, \& Agrigoroaei S (2015). Midlife as a Pivotal Period in the Life Course: Balancing Growth and Decline at the Crossroads of Youth and Old Age. Int J Behav Dev, 39(1), pp. 20-31. doi:10.1177/0165025414533223 [PubMed: 25580043]

Linn MW, Sandifer R, \& Stein S (1985). Effects of unemployment on mental and physical health. American Journal of Public Health, 75(5), pp. 502-506. [PubMed: 3985238]

McPhail SM, Schippers M, Marshall AL, Waite M, \& Kuipers P (2014). Perceived barriers and facilitators to increasing physical activity among people with musculoskeletal disorders: a qualitative investigation to inform intervention development. Clin Interv Aging, 9, pp. 2113-2122. doi:10.2147/cia.s72731 [PubMed: 25584023]

Pederson JL, Warkentin LM, Majumdar SR, \& McAlister FA (2016). Depressive symptoms are associated with higher rates of readmission or mortality after medical hospitalization: A systematic review and meta-analysis. Journal of hospital medicine

Peterson JC, Charlson ME, Hoffman Z, Wells MT, Wong SC, Hollenberg JP, . . Allegrante JP (2012). A randomized controlled trial of positive-affect induction to promote physical activity after percutaneous coronary intervention. Arch Intern Med, 172(4), pp. 329-336. doi:10.1001/ archinternmed.2011.1311 [PubMed: 22269589]

Piazza JR, Charles ST, \& Almeida DM (2007). Living with chronic health conditions: Age differences in affective well-being. The Journals of Gerontology Series B: Psychological Sciences and Social Sciences, 62(6), pp. P313-P321.

Saint Onge JM, Krueger PM, \& Rogers RG (2014). The relationship between major depression and nonsuicide mortality for U.S. adults: the importance of health behaviors. J Gerontol B Psychol Sci Soc Sci, 69(4), pp. 622-632. doi:10.1093/geronb/gbu009 [PubMed: 24569003]

Scheier MF, Carver CS, \& Bridges MW (1994). Distinguishing optimism from neuroticism (and trait anxiety, self-mastery, and self-esteem): a reevaluation of the Life Orientation Test. Journal of Personality and Social Psychology, 67(6), pp. 1063-1078. doi:10.1037/0022-3514.67.6.1063 Retrieved from 10.1037/0022-3514.67.6.1063http://www.ncbi.nlm.nih.gov/pubmed/7815302 Retrieved from http://www.ncbi.nlm.nih.gov/pubmed/7815302 [PubMed: 7815302]

Sin NL, Moskowitz JT, \& Whooley MA (2015). Positive Affect and Health Behaviors Across 5 Years in Patients With Coronary Heart Disease: The Heart and Soul Study. Psychosomatic medicine, 77(9), pp. 1058-1066. doi:10.1097/psy.0000000000000238 [PubMed: 26428445]

Steptoe Deaton, \& Stone. (2015). Subjective wellbeing, health, and ageing. Lancet, 385(9968), pp. 640-648. doi:10.1016/s0140-6736(13)61489-0 [PubMed: 25468152]

Steptoe A, Dockray S, \& Wardle J (2009). Positive affect and psychobiological processes relevant to health. Journal of personality, 77(6), pp. 1747-1776. [PubMed: 19796062]

Sun Q, Townsend MK, Okereke OI, Franco OH, Hu FB, \& Grodstein F (2010). Physical activity at midlife in relation to successful survival in women at age 70 years or older. Arch Intern Med, 170(2), pp. 194-201. doi:10.1001/archinternmed.2009.503 [PubMed: 20101015]

Valenstein M, Vijan S, Zeber JE, Boehm K, \& Buttar A (2001). The cost-utility of screening for depression in primary care. Annals of Internal Medicine, 134(5), pp. 345-360. 
Walker ER, McGee RE, \& Druss BG (2015). Mortality in mental disorders and global disease burden implications: a systematic review and meta-analysis. JAMA psychiatry, 72(4), pp. 334-341. [PubMed: 25671328]

Watson D, Clark LA, \& Tellegen A (1988). Development and validation of brief measures of positive and negative affect: the PANAS scales. J Pers Soc Psychol, 54(6), pp. 1063-1070. [PubMed: 3397865]

White DK, Keysor JJ, Neogi T, Felson DT, LaValley M, Gross KD, . . Torner J (2012). When it hurts, a positive attitude may help: association of positive affect with daily walking in knee osteoarthritis. Results from a multicenter longitudinal cohort study. Arthritis care \& research, 64(9), pp. 13121319. [PubMed: 22504854]

Zigmond AS, \& Snaith RP (1983). The hospital anxiety and depression scale. Acta Psychiatr Scand, 67(6), pp. 361-370. [PubMed: 6880820] 
Table 1.

Baseline characteristics and mean self-report scores in total and by individual cohort

\begin{tabular}{|lcccc|}
\hline & $\begin{array}{l}\text { Total } \\
(\mathbf{N}=92)\end{array}$ & $\begin{array}{l}\text { REACH } \\
(\mathbf{N}=\mathbf{3 0})\end{array}$ & $\begin{array}{l}\text { QRDM } \\
(\mathbf{N}=\mathbf{2 9})\end{array}$ & $\begin{array}{l}\text { PEACE } \\
(\mathbf{N}=\mathbf{3 3})\end{array}$ \\
Demographic Characteristics & & & \\
Age (SD) & $66.6(11.8)$ & $67.0(13.1)$ & $70.0(9.1)$ & $63.3(12.2)$ \\
Sex - no. (\%) & & & & \\
Male & $53(57.6 \%)$ & $7(23.3 \%)$ & $25(86.2 \%)$ & $21(63.6 \%)$ \\
Female & $39(42.4 \%)$ & $23(76.7 \%)$ & $4(13.8 \%)$ & $12(36.4 \%)$ \\
Ethnicity - no. (\%) & & & & \\
Asian & $4(4.3 \%)$ & $2(6.6 \%)$ & $1(3.4 \%)$ & $1(3.1 \%)$ \\
Hispanic & $4(4.3 \%)$ & - & - & $4(12.1 \%)$ \\
Black & $9(9.8 \%)$ & $4(13.4 \%)$ & $1(3.4 \%)$ & $4(12.1 \%)$ \\
White & $75(81.6 \%)$ & $24(80 \%)$ & $27(93.2 \%)$ & $24(72.7 \%)$ \\
Marital status - no. (\%) & & & & \\
Single & $16(17.4 \%)$ & $7(23.3 \%)$ & $4(13.8 \%)$ & $5(15.1 \%)$ \\
Married & $59(64.1 \%)$ & $16(53.3 \%)$ & $21(72.4 \%)$ & $22(66.7 \%)$ \\
Widowed & $9(9.8 \%)$ & $5(16.7 \%)$ & $2(6.9 \%)$ & $2(6.1 \%)$ \\
Divorced & $8(8.7 \%)$ & $2(6.7 \%)$ & $2(6.9 \%)$ & $4(12.3 \%)$ \\
Psychological Characteristics (mean (SD)) & & \\
LOT-R Total (SD) & $24.4(5.7)$ & $24.8(5.2)$ & $23.8(5.6)$ & $24.7(6.4)$ \\
LOT-R Optimism & $12.5(3.0)$ & $12.7(2.5)$ & $12.4(2.8)$ & $12.7(3.7)$ \\
LOT-R Pessimism & $11.9(3.5)$ & $12.1(3.6)$ & $11.3(3.6)$ & $12.3(3.5)$ \\
HADS Total & $11.6(6.9)$ & $11.6(6.8)$ & $9.2(5.1)$ & $13.8(7.9)$ \\
HADS Anxiety & $6.7(4.5)$ & $6.6(4.8)$ & $4.9(2.9)$ & $8.3(4.9)$ \\
HADS Depression & $5.0(3.4)$ & $5.1(3.0)$ & $4.3(2.8)$ & $5.5(4.2)$ \\
PANAS Positive Affect & $34.9(7.8)$ & $34.0(8.0)$ & $33.9(6.5)$ & $36.5(8.6)$ \\
\hline
\end{tabular}

HADS = Hospital Anxiety and Depression Scale;

LOT-R = Life Orientation Test-Revised;

PANAS $=$ Positive and Negative Affect Schedule;

$\mathrm{SD}=$ Standard Deviation 
Table 2.

Differences in positive and negative psychological variables between mid-life and non-mid-life participants.

\begin{tabular}{|lcccc|}
\hline Self-Report Measures & $\begin{array}{c}\text { Mid-Life } \\
(\mathbf{n}=\mathbf{3 0}) \\
\text { Mean (SD) }\end{array}$ & $\begin{array}{c}\text { Non-mid-life } \\
\mathbf{( n = 6 2 )} \\
\mathbf{M e a n}(\mathbf{S D})\end{array}$ & $\mathbf{t}$ & P-value \\
HADS & $13.8(7.3)$ & $10.6(6.5)$ & 2.14 & $0.035^{*}$ \\
HADS Anxiety & $7.9(4.4)$ & $6.1(4.5)$ & 1.80 & 0.074 \\
HADS Depression & $5.9(3.7)$ & $4.5(3.1)$ & 1.95 & 0.054 \\
PANAS & $32.6(8.3)$ & $36.0(7.3)$ & 1.93 & 0.056 \\
LOT-R & $23.9(6.4)$ & $24.7(5.4)$ & 0.61 & 0.54 \\
LOT-R Pessimism & $11.7(3.7)$ & $12.1(3.4)$ & 0.50 & 0.62 \\
LOT-R Optimism & $12.2(3.1)$ & $12.6(3.0)$ & 0.56 & 0.57 \\
Self-Report Measures & $\begin{array}{c}\text { Mid-Life } \\
(\text { excluding age }<50)\end{array}$ & $\begin{array}{c}\text { Non-mid-life } \\
(\mathbf{n}=\mathbf{5 4})\end{array}$ & $\mathbf{t}$ & $\mathbf{P}$-value \\
HADS & $\begin{array}{c}\text { Mean (SD) } \\
\text { Mean (SD) }\end{array}$ & & \\
HADS Anxiety & $13.8(7.2)$ & $9.9(6.3)$ & 2.53 & $0.013^{*}$ \\
HADS Depression & $5.9(4.4)$ & $5.6(4.0)$ & 2.41 & $0.018^{*}$ \\
PANAS Positive Affect & $32.6(8.3)$ & $35.6(7.5)$ & 1.69 & 0.09 \\
LOT-R & $23.9(6.4)$ & $25.0(5.2)$ & 0.84 & 0.39 \\
LOT-R Pessimism & $11.7(3.7)$ & $12.5(3.1)$ & 1.02 & 0.30 \\
LOT-R Optimism & $12.2(3.1)$ & $12.5(3.1)$ & 0.43 & 0.67 \\
\hline
\end{tabular}

HADS = Hospital Anxiety and Depression Scale;

LOT-R = Life Orientation Test-Revised;

PANAS = Positive and Negative Affect Schedule;

$\mathrm{SD}=$ Standard Deviation

p-value $<.05$ 
Table 3.

Between-group comparisons on themes from qualitative interview.

\begin{tabular}{|lcccc|}
\hline Theme & Mid-Life & Non-mid-life & $\chi^{2}$ & P-value \\
Energy & $13 / 28(46.4 \%)$ & $34 / 60(56.7 \%)$ & 0.80 & 0.37 \\
Medical comorbidities & $16 / 28(57.1 \%)$ & $41 / 60(68.3 \%)$ & 1.05 & 0.30 \\
Pain & $5 / 28(17.8 \%)$ & $14 / 60(23.3 \%)$ & 0.34 & 0.56 \\
Arthritis & $1 / 28(3.6 \%)$ & $8 / 60(13.3 \%)$ & 1.98 & 0.15 \\
Occupational stress & $17 / 28(60.7 \%)$ & $5 / 60(8.3 \%)$ & 27.94 & $0.001^{*}$ \\
Caregiving & $12 / 28(42.8 \%)$ & $8 / 60(13.3 \%)$ & 9.47 & $0.02^{*}$ \\
Financial stress & $9 / 28(32.1 \%)$ & $5 / 60(8.3 \%)$ & 8.09 & $0.004^{*}$ \\
Time burden & $22 / 28(78.6 \%)$ & $10 / 60(16.7 \%)$ & 31.61 & $0.001^{*}$ \\
Theme & Mid-Life & Non-mid-life & $\chi^{2}$ & P-value \\
Energy & $13 / 28(46.4 \%)$ & $30 / 52(57.7 \%)$ & 0.93 & 0.33 \\
Medical comorbidities & $16 / 28(57.1 \%)$ & $38 / 52(73.1 \%)$ & 2.10 & 0.15 \\
Pain & $5 / 28(17.8 \%)$ & $13 / 52(25.0 \%)$ & 0.53 & 0.47 \\
Arthritis & $1 / 28(3.6 \%)$ & $8 / 52(15.4 \%)$ & 2.54 & 0.11 \\
Occupational stress & $17 / 28(60.7 \%)$ & $2 / 52(3.8 \%)$ & 32.50 & $0.001^{*}$ \\
Caregiving & $12 / 28(42.8 \%)$ & $6 / 52(11.5 \%)$ & 10.24 & $0.001^{*}$ \\
Financial stress & $9 / 28(32.1 \%)$ & $3 / 52(5.8 \%)$ & 9.93 & $0.002^{*}$ \\
Time burden & $22 / 28(78.6 \%)$ & $8 / 52(15.4 \%)$ & 31.00 & $0.001^{*}$ \\
\hline
\end{tabular}

p-value $<.05$ 
Table 4.

Representative quotes from mid-life participants regarding stressors' impact on health behaviors.

\begin{abstract}
Occupational stress
- I've had high-pressure, high-stress jobs, jobs that don't end at five o 'clock in the afternoon...I think the load I have in terms of work, it's too, too high... What I call it is 'plates begin to drop' once it starts to get above a certain point. I lose control of it and then I really give up [on
\end{abstract} changing health behaviors]. (ID-8-QRDM)

\title{
Caregiving stress
}

- I had a phenomenal mom and she had breast cancer, and she was dying and I took off and I... I literally took a year off and I took care of my mother: (ID-31-REACH)

- My wife likes to play tennis so we play tennis together. But we just haven't played since the baby [was born]. (ID-18-PEACE)

\section{Financial stress}

- If you want to make any money and pay bills, you got to work all the time. Your day is gone

working 12 hours a day, seven days a week... working a lot of hours and overtime every day of the week, when you are busy, led to a lot of wrong things [regarding self-care]. (ID-25-QRDM)

\section{Multiple stressors}

- I think ofpressure.like my responsibility as a father and taking care of my house, everything else, my jobs...brought me a lot of stress. I used to do more exercise and be active... little by little the responsibility of the family, the kids, and I changed jobs so many times and that gave me a lot of stress. I had to pick and choose between taking care of my family and looking for the next job, or...taking care of myself. I was doing the right thing for my kids and my family, but not for myself so I felt like I was losing something, and I kept pushing myself until the heart attack. (ID-36- PEACE) 